ORIGINAL ARTICLE

\title{
Short and long term outcomes following partial exchange transfusion in the polycythaemic newborn: a systematic review
}

\section{E M Dempsey, K Barrington}

See end of article for authors' affiliations

Correspondence to: Dr Dempsey, Department of Neonatology, Coombe Womens Hospital, Dublin, Ireland; edempsey@ coombe.ie

Accepted 11 June 2005 Published online first 20 September 2005

Background: Severe polycythaemia in the neonate may produce symptoms due to hyperviscosity and may be associated with serious complications. Partial exchange transfusion will reduce the packed cell volume. Objective: To determine whether partial exchange transfusion in term infants with polycythaemia (symptomatic and asymptomatic) is associated with improved short and long term outcomes.

Search strategy: Medline, EMBASE, and the Cochrane Controlled Trials Register of the Cochrane Library were searched. The following keywords were used: polycythaemia, partial exchange transfusion, hyperviscosity, and limited to the newborn. This covered years 1966-2004. Abstracts of the Pediatric Academic Societies and personal files were also searched.

Selection criteria: Randomised or quasi-randomised trials in term infants with polycythaemia and/or documented hyperviscosity were considered. Clinically relevant outcomes included were short term (resolution of symptoms, neurobehavioural scores, major complications) and long term neurodevelopmental outcome.

Data collection and analysis: All data for each study were extracted, assessed, and coded separately. Any disagreements were resolved by discussion.

Main results: Six studies were identified; five had data that could be evaluated for analysis. There is no evidence of an improvement in long term neurological outcome (mental developmental index, incidence of mental delay, and incidence of neurological diagnoses) after partial exchange transfusion in symptomatic or asymptomatic infants. There is no evidence of improvement in early neurobehavioural assessment scores (Brazelton neonatal behavioural assessment scale). Partial exchange transfusion may be associated with an earlier improvement in symptoms, but there are insufficient data to calculate the size of the effect. Necrotising enterocolitis is probably increased by partial exchange transfusion (relative risk $8.68,95 \%$ confidence interval 1.06 to 71.1 .

Conclusion: There is no evidence of long term benefit from partial exchange in polycythaemic infants, and the incidence of gastrointestinal injury is increased. The long term outcome is more likely to be related to the underlying cause of polycythaemia.

$P$

olycythaemia occurs in $2-5 \%$ of term newborns, ${ }^{1}$ usually as a compensatory mechanism secondary to intrauterine fetal hypoxia, or sometimes as a result of delayed cord clamping. ${ }^{2}$ It leads to hyperviscosity, which can result in impaired end organ perfusion; this can manifest as neurological, ${ }^{3}$ cardiorespiratory, ${ }^{4}$ gastrointestinal, ${ }^{5}$ and metabolic ${ }^{6}$ symptoms. These symptoms are generally transient and may be minor despite severe degrees of polycythaemia. ${ }^{7}$ Although serious complications such as renal vein thrombosis or cerebral venous sinus thrombosis have been described in infants with polycythaemia, ${ }^{8}$ these are rare, and the principle clinical concern is that polycythaemia may be associated with adverse long term neurological sequelae.

Partial exchange transfusion (PET) has been used as a therapeutic modality to reduce packed cell volume and thereby blood viscosity while at the same time maintaining intravascular volume. ${ }^{9}$ Observational studies suggest that symptomatic infants who undergo PET may have an improvement in symptoms; however, the symptoms are in any case transient. More importantly, it is also unclear if PET is associated with improved long term neurological outcome. The objective of this systematic review was to assess the efficacy and safety of PET in the treatment of the polycythaemic newborn.

\section{METHODS}

\section{Criteria for inclusion}

Studies were included if they were randomised or quasirandomised clinical trials, if the participants were newborn with documented central polycythaemia (defined as a central packed cell volume greater than or equal to $64 \%$ ), and if the interventions consisted of a PET designed to reduce central packed cell volume to $60 \%$ or less, compared with observation only.

\section{Outcome measures}

(1) Long term neurodevelopmental, expressed as the proportion of infants with a neurological diagnosis, developmental delay, and/or motor abnormalities at 18 months or older. Alternatively, evaluation of cognitive or motor development using a validated continuous scale was acceptable.

(2) Short term neurological assessed by neurological and behavioural assessment scores.

Abbreviations: BNBAS, Brazelton neonatal behaviour assessment scale; NEC, necrotising enterocolitis; PET, partial exchange transfusion 


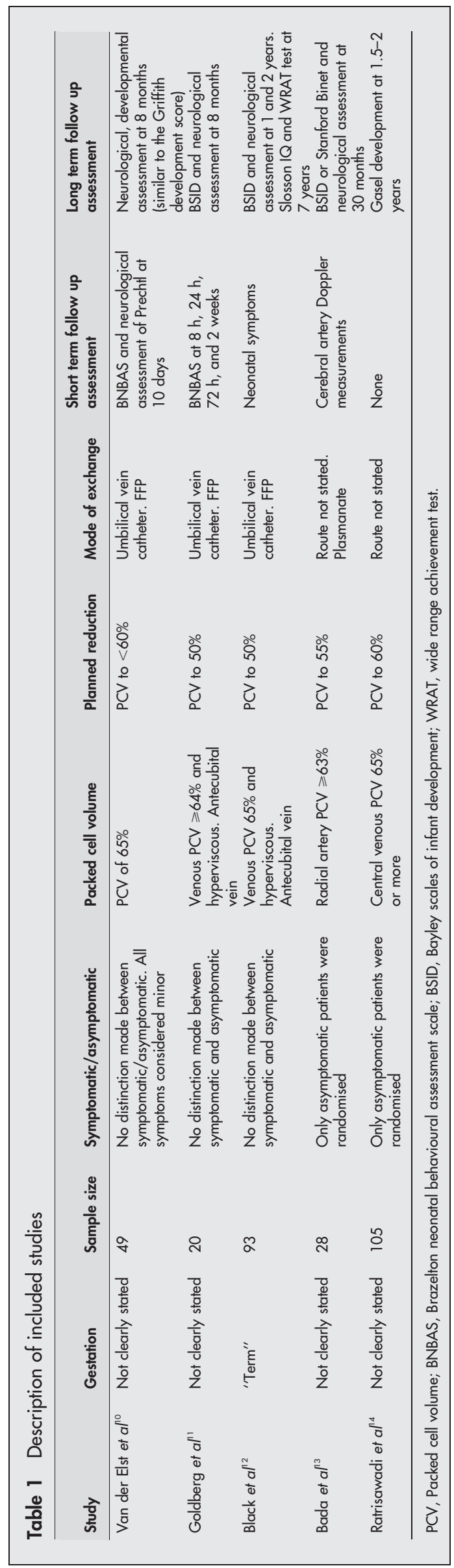

(3) Short term clinical as determined by resolution of symptoms attributed to polycythaemia.

(4) Adverse events.

\section{Search strategy for identification of studies}

The search was performed using Medline (1966-2005), EMBASE (1986-2005), and Cochrane Register of Controlled Trials. Keywords used were; polycythaemia, partial exchange transfusion, hyperviscosity, and limited to newborn. Abstracts from the Society for Pediatric Research were also reviewed. The search revealed 94 reports; each was inspected to determine their suitability for inclusion. Original papers were retrieved and reviewed. Citations from these papers were also assessed.

Each identified trial was assessed for methodological quality with respect to: (a) clear statement of inclusion and exclusion criteria; $(b)$ reliability of the method of randomisation including generation of randomisation sequence and masking of allocation; (c) masking of treatment groups at follow up; (d) completeness of follow up. We felt that masking of the intervention was not feasible. Where deemed appropriate, meta-analysis was performed using Revman 4.2 software using a random effects model. For dichotomous outcomes, we calculated a relative risk (RR) and 95\% confidence interval (CI), and for continuous variables a weighted mean difference and 95\% CI. Heterogeneity was evaluated using the $I^{2}$ statistic.

\section{RESULTS}

We identified a total of five randomised controlled trials of PET in newborns with polycythaemia or hyperviscosity: Van der Eelst et al, ${ }^{10}$ Goldberg et al, ${ }^{11}$ Black et al, ${ }^{12}$ Bada et al, ${ }^{13}$ and Ratrisawadi et al. ${ }^{14}$ A sixth study, published in abstract form, by Hakanson ${ }^{15}$ was excluded because of inadequate data availability. Table 1 provides a description of the included studies, and table 2 the methodological quality of each study.

\section{Analysis of outcomes}

Neurodevelopmental assessment at 18 months or older

Mental delay was assessed in two studies. ${ }^{12}{ }^{13}$ Bada et al ${ }^{13}$ presented both the mean scores and the number with "suspect/borderline mental retardation" (precise definition is not given). Black et al ${ }^{12}$ presented the proportion of infants with "mental delay" (not further defined). The summary estimate of the RR for the presence of developmental delay was 1.26 (95\% CI 0.62 to 2.56 ) (fig 1). The quasi-randomised study of Ratrisawadi et al ${ }^{14}$ had only $38 \%$ follow up at 2 years; abnormal developmental quotient was defined as less than 100 on the Gasel [sic] developmental test, present in 11/25 of infants treated with PET and 4/15 controls. This study had a lower quality assessment (based on method of allocation and low follow up rate). However, a sensitivity analysis including this study does not change the conclusion of no benefit on proportion with neurodevelopmental delay at $\geqslant 18$ months (RR $1.36,95 \%$ CI 0.78 to 2.41 ). At 7 years of age there was no difference between the groups in terms of intelligence quotient or scores on the wide range achievement test. ${ }^{16}$

The mean difference $(95 \%$ confidence interval (CI)) for mental developmental index in the study of Bada et all ${ }^{13}$ was $-3.0(-12.67$ to 6.67$)$. The presence of a neurological diagnosis was assessed in two studies ${ }^{12}{ }^{13}$; the summary estimate of the relative risk (RR) is 0.73 ( $95 \%$ CI 0.13 to 4.18 ) (fig 2). There is moderate heterogeneity for this outcome $\left(I^{2}\right.$ $=40.5 \%$.

\section{Short term neurobehavioural assessment}

Three studies ${ }^{10-12}$ present data on short term neurobehavioural outcome assessed by the Brazelton neonatal behaviour 
Table 2 Methodological quality of included studies

\begin{tabular}{|c|c|c|c|c|}
\hline Study & Inclusion/exclusion criteria & Randomisation & Masking of examiners & Completeness of follow up \\
\hline Van der Elst et $a l^{\circ}$ & Clearly stated & Not clearly stated & $\begin{array}{l}\text { Examiner was masked to } \\
\text { intervention status }\end{array}$ & $\begin{array}{l}\text { Exact percentage follow up at } \\
8 \text { months not stated }\end{array}$ \\
\hline Goldberg et $a l^{11}$ & Clearly stated & Not clearly stated & $\begin{array}{l}\text { Examiners were masked to } \\
\text { intervention status }\end{array}$ & $\begin{array}{l}\text { There was complete follow up in } \\
\text { the treated; } 60 \% \text { untreated }\end{array}$ \\
\hline Black et $a l^{12}$ & Clearly stated & $\begin{array}{l}\text { Drawing a card from deck } \\
\text { generated by a random } \\
\text { number table }\end{array}$ & Unclear & $\begin{array}{l}\text { Two year follow up of } 62 \% \text {. Some } \\
\text { data provided on failure of follow } \\
\text { up. } 7 \text { year follow up of } 49 / 93 \text {. }\end{array}$ \\
\hline Bada et $a l^{13}$ & Clearly stated & Not clearly stated & $\begin{array}{l}\text { Examiners were masked to } \\
\text { intervention status }\end{array}$ & Follow up was $67 \%$ \\
\hline Ratrisawadi et al ${ }^{14}$ & Clearly stated & Alternate assignment & Unclear & Follow up was $38 \%$ \\
\hline
\end{tabular}

assessment scale (BNBAS) and the Prechtl scale. Van der Elst et $a l^{10}$ found no difference between exchanged and observed groups in BNBAS and Prechtl scores at 10 days. Goldberg et a ${ }^{11}$ found a significant decrease in abnormalities initially present on BNBAS assessment when re-examined at two weeks only in the exchanged patients. Black et al ${ }^{12}$ mentioned that BNBAS was performed, but no data are presented. These studies do not allow us to make any firm conclusions as to the short term neurobehavioural effects of PET.

\section{Short term symptoms}

Most infants in these studies are asymptomatic. Van der Elst et $a l^{10}$ presented data on clinical signs and noted that peripheral cyanosis improved in all six patients, five after PET and one spontaneously in the observation group. Bada et $a l^{13}$ noted that clinical manifestations in the symptomatic polycythaemic group resolved $(87 \%)$ or became less severe ( $13 \%)$ after PET, and Black et al ${ }^{12}$ noted that gastrointestinal symptoms were common after PET. There are inadequate firm data to reach a conclusion.

\section{Adverse events}

Van der Elst et a ${ }^{10}$ noted that one of 24 patients developed necrotising enterocolitis (NEC) 24 hours after PET and required surgery. None of the 25 control patients developed NEC. There were no deaths. Black et al ${ }^{12}$ noted the onset of gastrointestinal symptoms in $42 \%$ of patients after PET and in only $2 \%$ of the controls. They also noted in a separate publication that eight of the 43 infants who had PET (and none of the 50 controls) developed typical NEC with pneumatosis and clinical symptoms. ${ }^{5}$ No adverse events were recorded in the studies of Goldberg et al, ${ }^{11}$ Bada et al, ${ }^{13}$ and Ratrisawadi et al. ${ }^{14}$ The RR for the development of NEC is 8.68 (95\% CI 1.06 to 71.1 ).

\section{DISCUSSION}

The current standard neonatal practice for performing a PET is (a) symptomatic with a packed cell volume of $65 \%$ or more ${ }^{17}$ or $(b)$ asymptomatic with a packed cell volume of $70 \%$ or more. The Committee of the Fetus and Newborn of the American Academy of Pediatrics does not issue any definitive guidelines, stating that the accepted treatment of polycythaemia is PET. ${ }^{18}$ We identified five randomised trials of PET in polycythaemic newborns. The studies have small numbers of patients, use various definitions of polycythaemia based on packed cell volume, and have various follow up times. Only two studies evaluated the efficacy of PET in studies limited to asymptomatic patients, ${ }^{13}{ }^{14}$ both using a packed cell volume of $65 \%$ or more.

There are no randomised trials of PET in only symptomatic patients, which reduces the power of this review to determine the effects of PET in such infants. This lack of information is not surprising as there is a tendency to treat all symptomatic patients with PET, probably because of published recommendations. ${ }^{17}$ However, there appears to be no clear evidence that the long term outcome of polycythaemic infants is worse in symptomatic patients, compared with those who were asymptomatic. Bada et $\mathrm{al}^{13}$ evaluated the long term outcome of the 10 non-randomised symptomatic infants in their study, which do not appear to be substantially different from the outcomes of the asymptomatic infants in the randomised trial-for example, the scores on the Bayley scales of infant development were almost identical $(90 \pm 13$ in the symptomatic infants compared with $85 \pm 9$ in the PET group and $88 \pm 13$ in the controls). Observational studies suggest that symptoms attributed to polycythaemia do improve after PET, ${ }^{19}{ }^{20}$ but these are in any case transient, and the lack of controls prevents us from drawing any firm conclusions about the effect of PET on timing of resolution of symptoms.

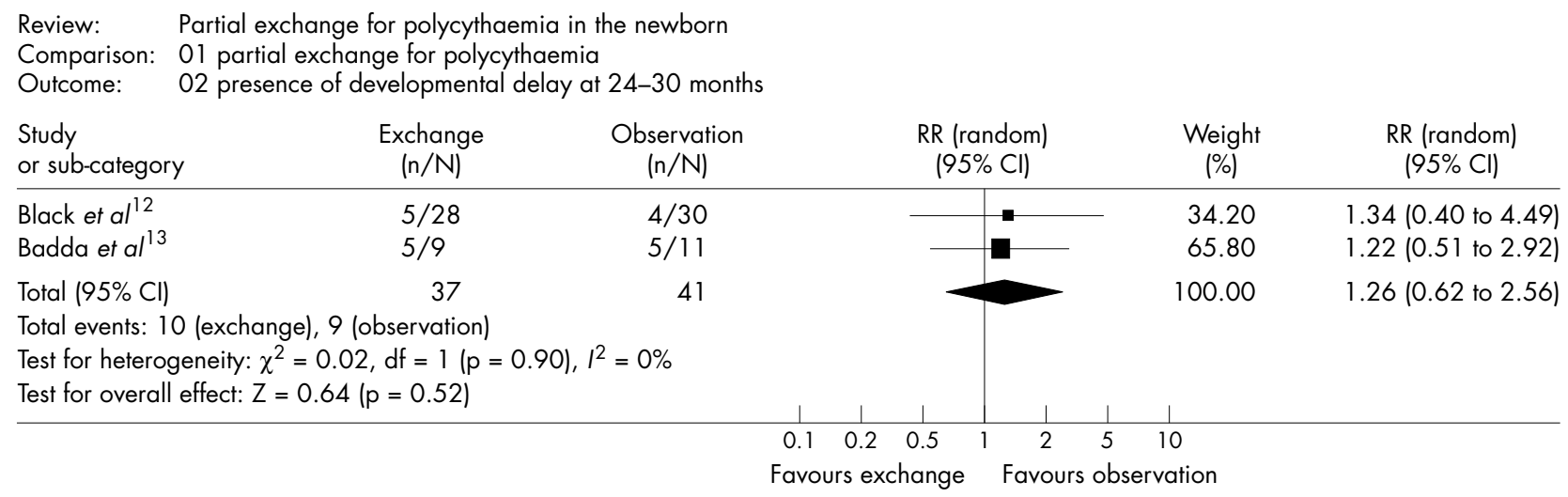

Figure 1 Forest plot of effect of partial exchange transfusion in polycythaemic newborn infants on the proportion of infants with developmental delay at 24-30 months of age. 
Review: Partial exchange for polycythaemia in the newborn

Comparison: 02 partial exchange for polycythaemia

Outcome: $\quad 04$ neurological diagnosis at 24-30 months

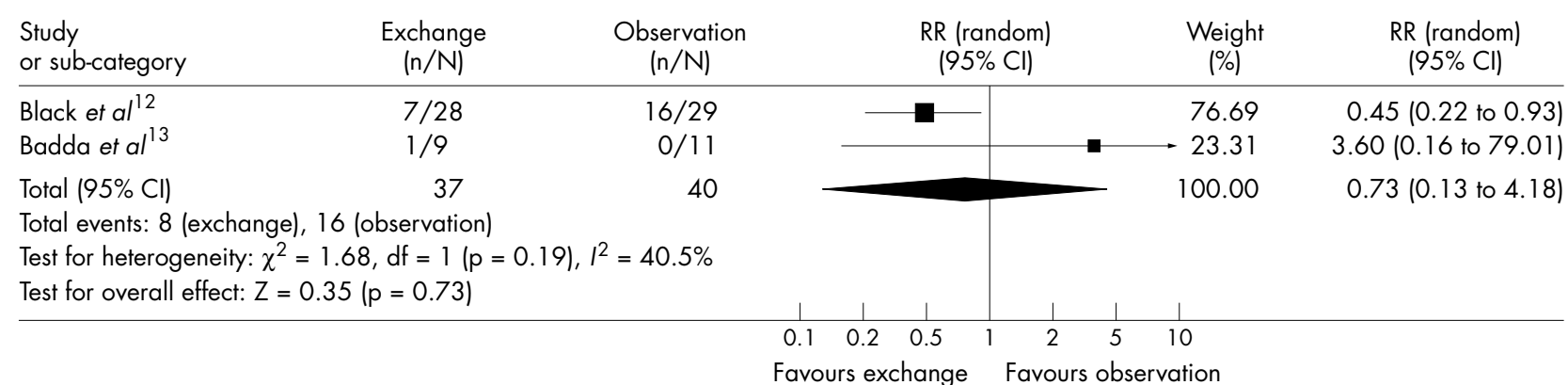

Figure 2 Forest plot of effect of partial exchange transfusion in polycythaemic newborn infants on the proportion of infants with a neurological diagnosis at 24-30 months of age. $\mathrm{RR}$, Relative risk; $\mathrm{Cl}$, confidence interval.

\section{What is already known on this topic}

- Polycythaemia occurs in $2-5 \%$ of term neonates

- Partial exchange transfusion is generally advocated when the packed cell volume is greater than $70 \%$ in asymptomatic patients or greater than $65 \%$ in symptomatic patients
None of the studies that included both symptomatic and asymptomatic infants provided long term follow up information based on symptomatology. In particular, patients with severe neurological symptomatology (such as seizures) have not been reported separately, thus a possibility remains that such infants may have a long term benefit. This, however, has not been demonstrated, highlighting the fact that there is no reliable evidence to support current practice.

The study by Bada et al ${ }^{13}$ of asymptomatic infants assessed at 24 months or greater was unable to show any effect of PET on long term neurodevelopmental outcome. We combined the findings of this study with those of the much larger study of Black et al $^{12}$ (including both symptomatic and asymptomatic infants) and still found no neurological benefit. Even follow up to 7 years did not reveal any significant differences between the groups. These data would seem to indicate that the cause of the impaired long term outcome is the cause of the polycythaemia, usually intrauterine fetal hypoxia. Bada et al, for example, were unable to find an effect of PET, but noted from multiple regression analysis that fetal distress, hypoglycaemia, and maternal pre-eclampsia were associated with poor outcome.

Although not a planned part of our analysis, data on medium term outcomes ( 8 months of age) were recorded in two studies. ${ }^{10}{ }^{11}$ Van der Elst et $a l^{10}$ reported that all infants followed to 8 months were neurologically normal and had "a developmental score appropriate for their age". Goldberg et $a l^{11}$ examined 10 PET treated and six control infants and found 5/10 compared with 4/6 had abnormal neurological findings and almost identical Bayley scores. These studies included symptomatic and asymptomatic infants. Although developmental testing at such an early age does not accurately predict later functioning, these results support the findings of the planned analyses that no clinically important advantage is gained from PET.

PET is not without complications; in the two studies that report NEC, 9/67 PET infants, compared with 0/75 controls developed this disorder. In both studies, PET was performed

\section{What this study adds}

- Partial exchange transfusion was not associated with an improvement in long term neurodevelopmental outcome in polycythaemic patients

- Umbilical partial exchange transfusion was associated with an increased risk of necrotising enterocolitis

by umbilical catheterisation. These data suggest a temporal and causative relation between NEC and umbilical PET. Thus the only apparent effect of PET from our analysis is an adverse outcome; however, many of the studies did not report the incidence of NEC, and the confidence intervals for this effect are very wide.

In conclusion, we could not find reliable evidence that there is a clinically important benefit from PET in infants with polycythaemia. There is, specifically, no evidence of a long term neurological benefit. Although the outcome of polycythaemic infants is poorer than that of concurrently enrolled infants without polycythaemia, ${ }^{11}{ }^{13}$ this is probably related to the underlying cause of polycythaemia, and is not improved by PET. It remains possible that infants with severe neurological symptoms could benefit from PET, as the literature does not appear to have enough power to eliminate such a benefit. However, for infants with no symptoms or only minor symptoms, such as most of the infants enrolled in these studies, the clinical decision of whether to intervene with PET should take into account the lack of demonstrated benefit and the apparent increase in necrotising enterocolitis.

\section{ACKNOWLEDGEMENTS}

EMD is funded by the Department of Pediatrics, McGill University, Clinical/Research Fellowship in Academic Pediatrics.

\section{Authors' affiliations}

E M Dempsey, K Barrington, Department of Pediatrics, McGill University Health Center, Montreal, Canada

Competing interests: none declared

\section{REFERENCES}

1 Ramamurthy RS, Brans YW. Neonatal polycythemia. I. Criteria for diagnosis and treatment. Pediatrics $1981 ; 68: 168-74$.

2 Rosenkrantz TS. Polycythemia and hyperviscosity in the newborn. Semin Thromb Hemost 2003;29:515-27.

3 Delaney-Black V, Camp BW, Lubchenco LO, et al. Neonatal hyperviscosity association with lower achievement and IQ scores at school age. Pediatrics $1989 ; 83: 662-7$ 
4 Saigal S, Usher RH. Symptomatic neonatal plethora. Biol Neonate 1977;32:62-72.

5 Black VD, Rumack CM, Lubchenco LO, et al. Gastrointestinal injury in polycythemic term infants. Pediatrics 1985;76:225-31.

6 Herson VC, Raye JR, Rowe JC, et al. Acute renal failure associated with polycythemia in a neonate. J Pediatr 1982;100:137-9.

7 Host A, Ulrich M. Late prognosis in untreated neonatal polycythemia with minor or no symptoms. Acta Paediatr Scand 1982;71:629-33.

8 Nowak-Gottl U, Kosch A, Schlegel N. Neonatal thromboembolism. Semin Thromb Hemost 2003:29:227-34.

9 Rosenkrantz TS, Oh W. Cerebral blood flow velocity in infants with polycythemia and hyperviscosity: effects of partial exchange with plasmanate. J Pediatr 1982;101:94-8.

10 Van der Elst CW, Molteno CD, Malan AF, et al. The management of polycythaemia in the newborn infant. Early Hum Dev 1980;4:393-403.

11 Goldberg K, Wirth FH, Hathaway WE, et al. Neonatal hyperviscosity. II. Effect of partial plasma exchange transfusion. Pediatrics 1982;69:419-25.

12 Black VD, Lubchenco LO, Koops BL, et al. Neonatal hyperviscosity: randomized study of effect of partial plasma exchange transfusion on longterm outcome. Pediatrics 1985;75:1048-53.
13 Bada HS, Korones SB, Pourcyrous $M$, et al. Asymptomatic syndrome of polycythemic hyperviscosity: effect of partial plasma exchange transfusion. J Pediatr 1992; 120:579-85.

14 Ratrisawadi V, Plubrukarn R, Trakulchang K, et al. Developmental outcome of infants with neonatal polycythemia. J Med Assoc Thai 1994;77:76-80.

15 Hakanson DO. Neonatal hyperviscosity syndrome: longterm benefit of partial plasma exchange transfusion [abstract]. Pediatr Res 1981;15:449A.

16 Delaney-Black V, Camp BW, Lubchenco LO, et al. Neonatal hyperviscosity association with lower achievement and IQ scores at school age. Pediatrics 1989:83:662-7

17 Oh W. Neonatal polycythemia and hyperviscosity. Pediatr Clin North Am 1986;33:523-32.

18 American Academy of Pediatrics, Committee on Fetus and Newborn Routine evaluation of blood pressure, $\mathrm{HCT}$ and glucose in newborns. Pediatrics 1993;92:474-6.

19 Deorari AK, Paul VK, Shreshta L, et al. Symptomatic neonatal polycythemia: comparison of partial exchange transfusion with saline versus plasma. Indian Pediatr 1995;32:1167-71.

20 Krishnan L, Rahim A. Neonatal polycythemia. Indian J Pediatr 1997;64:541-6.

\section{Clinical Evidence-Call for contributors}

Clinical Evidence is a regularly updated evidence-based journal available worldwide both as a paper version and on the internet. Clinical Evidence needs to recruit a number of new contributors. Contributors are healthcare professionals or epidemiologists with experience in evidence-based medicine and the ability to write in a concise and structured way.

Areas for which we are currently seeking contributors:

- Pregnancy and childbirth

- Endocrine disorders

- Palliative care

- Tropical diseases

We are also looking for contributors for existing topics. For full details on what these topics are please visit www.clinicalevidence.com/ceweb/contribute/index.jsp

However, we are always looking for others, so do not let this list discourage you.

Being a contributor involves:

- Selecting from a validated, screened search (performed by in-house Information Specialists) epidemiologically sound studies for inclusion.

- Documenting your decisions about which studies to include on an inclusion and exclusion form, which we keep on file.

- Writing the text to a highly structured template (about 1500-3000 words), using evidence from the final studies chosen, within 8-10 weeks of receiving the literature search.

- Working with Clinical Evidence editors to ensure that the final text meets epidemiological and style standards.

- Updating the text every 12 months using any new, sound evidence that becomes available. The Clinical Evidence in-house team will conduct the searches for contributors; your task is simply to filter out high quality studies and incorporate them in the existing text.

If you would like to become a contributor for Clinical Evidence or require more information about what this involves please send your contact details and a copy of your CV, clearly stating the clinical area you are interested in, to CECommissioning@bmigroup.com.

\section{Call for peer reviewers}

Clinical Evidence also needs to recruit a number of new peer reviewers specifically with an interest in the clinical areas stated above, and also others related to general practice. Peer reviewers are healthcare professionals or epidemiologists with experience in evidence-based medicine. As a peer reviewer you would be asked for your views on the clinical relevance, validity, and accessibility of specific topics within the journal, and their usefulness to the intended audience (international generalists and healthcare professionals, possibly with limited statistical knowledge). Topics are usually 1500-3000 words in length and we would ask you to review between 2-5 topics per year. The peer review process takes place throughout the year, and out turnaround time for each review is ideally 10-14 days.

If you are interested in becoming a peer reviewer for Clinical Evidence, please complete the peer review questionnaire at www. clinicalevidence.com/ceweb/contribute/peerreviewer.jsp 